\title{
Discapacidad y derecho a la igualdad en tiempos de pandemia
}

\author{
Deficiência e o direito à igualdade em tempos de pandemia
}

\author{
Disability and the right to equality in times of pandemic
}

Agustina Palacios*

\section{Resumen}

La situación de desigualdad estructural que viven las personas con discapacidad se ha acrecentado y agravado profundamente en el contexto de pandemia por Covid-19. Ello nos interpela a la necesaria deconstrucción de enfoques y perspectivas para alcanzar políticas públicas verdaderamente inclusivas. A través de estas líneas, se comparten algunas reflexiones tomando como punto de partida el "modelo de igualdad inclusiva" previsto en la Observación General Nro. 6 del Comité sobre los Derechos de las Personas con Discapacidad, que prevé cuatro dimensiones. En primer lugar, el derecho a la igualdad inclusiva debe tratar de corregir las desventajas - desde políticas redistributivas. En segundo lugar, debe contrarrestar los prejuicios, el estigma, los estereotipos, la humillación y la violencia basados en una diversidad funcional - políticas de reconocimiento y enfoque interseccional. En tercer lugar, debe ampliar la participación, contrarrestando la exclusión - esto es la plasmación del lema "nada sobre las personas con discapacidad sin las personas con discapacidad". Finalmente, debe ajustar la diferencia - para lo cual resulta ineludible la garantía del "derecho a la accesibilidad universal", que engloba asimismo sistemas de apoyo y ajustes razonables.

Palabras claves: Discapacidad. Igualdad. Pandemia.

\section{Resumo}

A situação de desigualdade estrutural vivida por pessoas com deficiência aumentou e se aprofundou no contexto da pandemia da Covid-19. Isso nos desafia para a necessária desconstrução de abordagens e perspectivas para o alcance de políticas públicas verdadeiramente inclusivas. Nestas linhas, algumas reflexões são compartilhadas, partindo-se do "modelo de igualdade inclusiva" previsto no Comentário Geral n. ${ }^{\circ} 6$ do Comitê dos Direitos das Pessoas com Deficiência, que apresenta quatro dimensões. Primeiro, o direito à igualdade inclusiva deve tentar corrigir as desvantagens - das políticas redistributivas. Em segundo lugar, deve combater as perdas, o estigma, os estereótipos, a humilhação e a violência com base na diversidade funcional - políticas de reconhecimento e abordagem interseccional. Em terceiro lugar, deve ampliar a participação, opondo-se à exclusão - esta é a expressão do slogan "nada sobre as pessoas com deficiência sem as pessoas com deficiência". Por último, é necessário ajustar a diferença - para o qual há a garantia do "direito à acessibilidade universal", que inclui também sistemas de apoio e ajustes razoáveis.

Palavras-chave: Deficiência. Igualdade. Pandemia.

\section{Abstract}

The situation of structural inequality experienced by people with disabilities has increased and worsened deeply in the context of the COVID-19 pandemic. This calls us to the necessary deconstruction of approaches and perspectives to achieve truly inclusive public policies. Through these lines, some reflections are shared taking as a starting point the "inclusive equality model" provided for in General Comment No. 6 of the Committee on the Rights of Persons with Disabilities, which provides four dimensions. In the first place, the right to inclusive equality must try to correct the disadvantages - from redistributive policies. Second, it must counter prejudice, stigma, stereotypes, humiliation and violence based on functional diversity recognition policies and an intersectional approach. Third, it must expand participation, counteracting exclusion - this is the embodiment of the slogan "nothing about people with disabilities without people with disabilities". Finally, it must adjust the difference - for which the guarantee of the "right to universal accessibility" is unavoidable, which also includes support systems and reasonable accommodation.

Keywords: Disability. Equality. Pandemic.

Doctora en Derecho por la Universidad Carlos III de Madrid. Programa Derechos Humanos, Instituto de Derechos Humanos "Bartolomé de las Casas". Profesora Adjunta de Derecho Político y Profesora de Derechos Humanos y Garantías Constitucionales, Facultad de Derecho, Universidad Nacional de Mar del Plata. Investigadora Adjunta del CONICET (Consejo Nacional de Investigaciones Científicas y tecnológicas de Argentina). Directora del Área Discapacidad y Derechos Humanos, Centro de Investigación y Docencia en Derechos Humanos "Alicia Moreau", Facultad de Derecho, Universidad Nacional de Mar del Plata. Relatora Argentina de la Red Iberoamericana de Expertos en la Convención Internacional sobre los Derechos de las Personas con Discapacidad. Directora Grupo de Investigación sobre Discapacidad, Sociedad y Derechos Humanos, Facultad de Derecho, Universidad Nacional de Mar del Plata (OCA 108/2012). Directora de la Clínica Jurídica en Discapacidad y Derechos Humanos", Facultad de Derecho, Universidad Nacional de Mar del Plata. Mar del Plata - Argentina. E-mail: aguspalacios@hotmail.com. 


\section{Introducción}

No resulta novedoso para las personas con discapacidad enfrentar barreras de participación en la comunidad, ni tampoco tener menos probabilidades de acceso a la atención sanitaria, a la educación y al empleo. Los datos de la realidad reflejan mayores probabilidades de vivir en la pobreza, exposición a tasas de violencia, abandono y abuso más elevadas, entre un largo etcétera que les coloca entre los colectivos en mayor situación de vulnerabilidad (ONU, 2020b). La pandemia ha agravado intensamente esta situación. A las barreras que enfrentan a diario - estigmatización, falta de acceso a bienes y servicios básicos, pobreza, invisibilidad y abandono o institucionalización -, se suman las nuevas generadas por el Covid-19, y con ello la profundización de una desigualdad estructural que se encuentra tristemente normalizada, y que sin duda repercute en que el colectivo de personas con discapacidad se encuentre entre los más afectados por esta crisis en cuanto a muertes (ONU, 2020b).

Se ha expresado que el virus es potencialmente democrático, dado que no discrimina (OXFAM, 2020). Sin embargo, cabe hacer tres matices (PALACIOS; GONZALEZ BONET, 2020).

El primero se relaciona con el mayor riesgo que tienen algunas personas con discapacidad de de contraer Covid-19, ya sea como consecuencia de las barreras que enfrentan para acceder a la información preventiva y la higiene, la necesidad de contacto con el medio ambiente o con las personas de apoyo, así como las afecciones respiratorias que pueden afectar a algunas de ellas (IDA, 2020).

El segundo se vincula con la exposición de las personas con discapacidad, al contraer Covid-19, de enfrentar barreras adicionales para recibir atención médica, como asimismo experimentar discriminación y negligencia por parte del personal sanitario (IDA, 2020).

Finalmente, no es posible ignorar que los efectos de las políticas adoptadas sí pueden originar una amplia gama de consecuencias discriminatorias, producto de las respuestas estatales frente a la crisis, que subrayan las profundas desigualdades dentro de nuestras sociedades (ONU, 2020c). Ello se refleja en directrices y protocolos médicos selectivos que pueden aumentar la discriminación en el acceso a servicios de salud, revelando prejuicios respecto de las personas con discapacidad, su calidad de vida y su valor social (IDA, 2020).

A lo expresado se suma el hecho de que a la discriminación no se llega solo mediante políticas o normas que impliquen diferenciaciones injustas, sino también mediante omisiones que no tengan en cuenta la perspectiva de discapacidad, los ajustes que pueden requerir las personas con discapacidad, ni la situación/ posición previa de discriminación estructural. ${ }^{1}$

El panorama descrito nos interpela urgentemente a la necesaria deconstrucción de enfoques y perspectivas para alcanzar políticas públicas verdaderamente inclusivas. A través de estas líneas, se comparten algunas reflexiones, tomando como punto de partida el "modelo de igualdad inclusiva" previsto en la Observación General Nro. 6 del Comité sobre los Derechos de las Personas con Discapacidad. ${ }^{2}$

\section{Discapacidad y derecho a la igualdad inclusiva}

La política pública en materia de discapacidad debe apoyarse, al menos, en dos columnas rectoras erigidas desde un enfoque de derechos humanos y una perspectiva de discapacidad (PALACIOS, 2019). Si bien los derechos humanos han sido caracterizados por su universalidad, hasta hace pocos años tenían asignaturas pendientes en relación a las personas con discapacidad (DE ASIS ROIG, 2013). Fue por ello que debieron nutrirse de contenido en la materia. Y ese contenido lo aportó el movimiento de personas con discapacidad y la construcción de un modelo social de discapacidad (BARNES; OLIVER; BARTON, 2002). Desde estos ámbitos (activismo político y academia) se brindaron fundamentos para la deconsrtucción de

Parte de las reflexiones expuestas en este trabajo se encuentran desarrolladas con mayor profundidad en: Palacios, A.; González Bonet, V. (2020). CRPD/C/GC/6, Aprobada por el Comité en su $19^{\circ}$ período de sesiones (14 de febrero a 9 de marzo de 2018). 
la misma noción de discapacidad, superando un enfoque médico-rehabilitador que la entendía como una limitación individual de una persona, para pasar a concebirla como una situación - y posición - resultante de la interacción entre una persona y las barreras sociales.

Desde hace algunas décadas el mismo modelo social está siendo objeto de profundas críticas (FERRANTE, 2020), que seguramente promoverán las bases para una segunda o tercera ola del modelo social (PALACIOS, 2019). Así, ya sea desde la propuesta de un modelo de la diversidad (ROMANACH, 2007), desde un nuevo discurso como el de capacitisimo (TOBOSO, 2017), desde la defensa del derecho a la locura (CEA-MADRID, 2019), desde los estudios críticos de discapacidad desde el Sur Global, (YARZA DE LOS RIOS et al, 2019), desde las teorías crip (MCRUER, 2018), entre otras.

Sin pretender obviar dichas teorías - algunas complementarias y otras críticas del modelo social -, a los efectos del presente trabajo interesa destacar que la discapacidad tiene, al menos, tres dimensiones. La primera es la condición de discapacidad, que es la dimensión personal. El modo en que se defina y conciba esta condición sin duda va a tener incidencia en la identidad de la persona. Si la mirada surge exclusivamente desde un diagnóstico médico -como el de deficiencia -, entonces se convierte en una identidad de la insuficiencia, la carencia y la falta de autonomía. La segunda dimensión a tener en cuenta es la situación de discapacidad. La dimensión interrelacional, situacional y dinámica que surge cuando entran en juego las barreras sociales (BROGNA, 2009). Esta situación es en verdad la que "discapacita", restringe y/o impide el ejercicio de derechos en igualdad de condiciones con las demás personas. Ha sido puesta de manifiesto desde el activismo político y el modelo social de discapacidad desde la década de los años setenta del siglo pasado. La tercera dimensión es la posición de discapacidad, que es estructural. Se sitúa en las representaciones, en las valoraciones, en la cultura, siendo el resultado de nuestros prejuicios y estereotipos. Es necesario, por ende, tomar conciencia respecto de que la posición de discapacidad se relaciona con el valor que le asignamos a esa condición y a esa situación (FERREIRA, 2008).

Estas tres dimensiones nos advierten que, al analizar la discapacidad en el contexto de la pandemia, nos encontramos ante situaciones y posiciones previas de vulnerabilidad, que claramente se potencian y acrecientan.

Desde el derecho internacional de los derechos humanos se han elaborado instrumentos y resoluciones mediante los cuales se ha visibilizado a las personas con discapacidad, y sobre todo la situación de acrecentamiento de desigualdades que exigen medidas, sin duda urgentes por parte de los Estados ( $y$ entiendo que incluso también por parte de los organismos que integran los sistemas de protección de derechos humanos).

Previo adentrarnos en algunos de dichos estándares, cabe recordar que el enfoque de derechos humanos y la perspectiva de discapacidad nos conducen a un instrumento que, tanto en el derecho internacional de los derechos humanos como en los propios Estados, ${ }^{3}$ ha visibilizado la situación de discriminación estructural en la que viven las personas con discapacidad, ha insertado la cuestión de la discapacidad dentro de la agenda de derechos humanos (y viceversa, los derechos humanos en la agenda de la discapacidad), y ha demostrado que se puede (y debe) habilitar la participación de las personas con discapacidad en todo proceso de elaboración de leyes y políticas públicas que les afecte.

La Convención Internacional sobre los Derechos de las Personas con Discapacidad sitúa a la persona con discapacidad como sujeto de derecho. Plasma el modelo social, y obliga a adoptar la "perspectiva" de derechos humanos. Persigue "promover, proteger y asegurar el goce pleno y en condiciones de igualdad de todos los derechos humanos y libertades fundamentales por todas las personas con discapacidad, y promover el respeto de su dignidad inherente". ${ }^{4}$

Sus principios son una obligación, un faro y un parámetro a tener en cuenta tanto al momento de interpretar, como de aplicar el Derecho y de diseñar e implementar políticas públicas. Y dentro de las luces

Convención Internacional sobre los Derechos de las Personas con Discapacidad que entró en vigor en el año 2008.

Artículo $1^{\circ}$ de la Convención sobre los Derechos de las Personas con Discapacidad. 
que conforman este faro, uno de los valores/principios/derechos claves en este Tratado ha sido y es la igualdad. La igualdad en el contexto de la discapacidad exige la inclusión de la diversidad. En el contexto del derecho internacional de los derechos humanos, ello ha sido reforzado a través de las diversas dimensiones que incorpora la CDPD - como principio, como valor y como derecho. Durante su proceso de gestación, se trabajó teniendo en miras una igualdad de oportunidades. Se entendió que el modelo de igualdad de oportunidades en materia de igualdad, enfocaba adecuadamente las cuestiones sobre el uso negativo de la diferencia prohibiendo la discriminación basada en discapacidad, a la vez que imponiendo acciones positivas (QUINN, 2006).

La Convención asume, a través de sus principios, y en la regulación de los derechos que ampara, una concepción amplia de la igualdad, que no se queda en un simple trato no discriminatorio —igualdad formal-, sino que asume la igualdad de oportunidades, que requiere en ciertos casos de medidas activas —igualdad material—, que debe pasar necesariamente por el respeto por la diferencia y la aceptación de las personas con discapacidad como parte de la diversidad y la condición humanas; ello implica necesariamente la adopción de políticas de reconocimiento, que tiendan a alcanzar una participación e inclusión plenas y efectivas en la sociedad.

Profundizando su contenido y alcance, en los últimos años se ha estado desarrollando un nuevo modelo de igualdad en el contexto de la discapacidad (GOLDSCHMIDT, 2017). En el año 2018 el Comité sobre los Derechos de las Personas con Discapacidad aprobó la Observación General Nro. 6 sobre Igualdad y No Discriminación (de aquí en adelante OG6). El instrumento destaca que "la igualdad de oportunidades, como principio general de la Convención en virtud del artículo 3, constituye un paso importante en la transición de un modelo de igualdad formal a un modelo de igualdad sustantiva. La igualdad formal lucha contra la discriminación directa tratando de manera similar a las personas que están en situación similar. Puede ayudar a combatir los estereotipos negativos y los prejuicios, pero no puede ofrecer soluciones al "dilema de la diferencia", ya que no tiene en cuenta las diferencias entre los seres humanos. La igualdad sustantiva, en cambio, aborda también la discriminación indirecta y estructural, y tiene en cuenta las relaciones de poder. Admite que el "dilema de la diferencia" entraña tanto ignorar las diferencias entre los seres humanos como reconocerlas (...). ${ }^{5}$ La OG6 propone, entonces, un nuevo modelo de igualdad que se desarrolla a lo largo de toda la Convención, que abarca un modelo de igualdad sustantiva, pero que al mismo tiempo amplía y detalla el contenido de la igualdad a través de una serie de dimensiones. ${ }^{6}$

El modelo planteado por el Comité tiene una indudable influencia del trabajo de Sandra Fredman, quien desde el desarrollo de la igualdad sustantiva propone una reconceptualización, a partir del establecimiento de un marco de cuatro dimensiones de fines y objetivos (FREDMAN, 2016). Este enfoque - cuatridimensional - busca proporcionar un marco analítico para iluminar la naturaleza multifacética de la desigualdad y ayudar a determinar si las acciones, prácticas o instituciones lo impiden o promueven. Se encuentra enmarcado en términos de dimensiones, para permitir centrarnos en su interacción y sinergias. De este modo, ante la existencia de conflictos, o entrecruzamientos entre las diversas dimensiones, la tensión podría resolverse haciendo referencia al marco en su conjunto, con el objetivo, no tanto de insistir en que una tenga prioridad sobre otra, sino de crear una síntesis que las tenga en cuenta a todas (FREDMAN et al, 2017).

Las cuatro dimensiones que exige el modelo de igualdad inclusiva requieren profundizar asimismo, en ciertos principios clave en materia de discapacidad. En primer lugar, el derecho a la igualdad inclusiva debe tratar de corregir las desventajas - desde políticas redistributivas. En segundo lugar, debe contrarrestar los prejuicios, el estigma, los estereotipos, la humillación y la violencia basados en una condición de discapacidad -políticas de reconocimiento de la diversidad funcional como parte de la condición de humanidad. ${ }^{7}$ En tercer lugar, debe ampliar la voz y la participación, contrarrestando la exclusión política y social - esto es la plasmación del lema "nada sobre las personas con discapacidad sin las personas con discapacidad".

OG6 CDPD, párr.10.

Idem.

En el sentido que le brinda el art. 3 inc. d) de la Convención Internacional sobre los Derechos de las Personas con Discapacidad 
Incluyendo, asimismo, la perspectiva de interseccionalidad. Finalmente, debe ajustar la diferencia y proponer un cambio estructural -para lo cual resulta ineludible la garantía del "derecho a la accesibilidad universal", que engloba asimismo sistemas de apoyo y ajustes razonables.

En lo que sigue se comparten unas incipientes reflexiones sobre la pertinencia de este modelo de igualdad en materia de discapacidad, ${ }^{8}$ y que pretenden reflejar la necesidad de un mayor desarrollo de sus cuatro dimensiones en el contexto de la pandemia.

\section{La igualdad inclusiva en el contexto de pandemia}

Desde el sistema de protección internacional de los derechos humanos se han emitido recomendaciones y reafirmado estándares existentes en materia de discapacidad, con una clara especificación en el contexto de la pandemia. El modelo de igualdad inclusiva que instaura el Comité podría resultar una buena orientación en este contexto. Es por ello que en lo que sigue se identifican determinadas medidas y obligaciones estatales a la luz de las cuatro dimensiones mencionadas.

\subsection{Una dimensión redistributiva justa para afrontar las desventajas socioeconómicas}

La primera dimensión que identifica la OG6 se relaciona con la dimensión redistributiva. Es sabido que existe un vínculo directo entre pobreza y discapacidad. Según la Organización Internacional del Trabajo el $82 \%$ de las personas con discapacidad están bajo la línea de pobreza, esto deviene de la falta de acceso al empleo, pero también de que deben incurrir en mayores gastos durante sus vidas (OIT, 2020). Pero el tema es aún más complejo. Las teorías económicas sobre desarrollo han omitido cuestiones esenciales sobre el colectivo de personas con discapacidad, contribuyendo a su invisibilidad y pobreza (MARTINEZ RIOS, 2018). Los costes extraordinarios derivados de la discapacidad y de las barreras a las cuales se enfrentan las personas con discapacidad contribuyen a su pobreza, falta de libertad y vulneración de derechos humanos. El colectivo es uno de los que representa mayores niveles de exclusión social en términos de distribución de recursos y bienes. La situación de pobreza comúnmente se concibe como la imposibilidad en que se encuentra una persona para cubrir sus necesidades básicas, razón por la cual suele medirse en términos de ingresos y nivel de renta. Sin embargo, "dicho baremo de medición presenta algunos inconvenientes para el tema de la discapacidad, toda vez que una persona que se encuentra en esta situación, incluso con un nivel de ingresos aceptable, puede hallarse en posición de desventaja respecto a otra persona sin discapacidad, aun cuando los ingresos de esta última sean ostensiblemente inferiores" (OSPINA, 2018, s.p.).

En este contexto, incluso si admitiéramos que el virus no discrimina, sí lo hace su impacto económico, y por ello es necesario desarrollar políticas que garanticen, entre otras medidas, ingresos mínimos a las personas en situación de mayor vulnerabilidad ante la crisis (OXFAM, 2020). La Comisión Interamericana de Derechos Humanos destaca que es necesario disponer y movilizar el máximo de los recursos disponibles para hacer efectivos los derechos y con el objeto de prevenir y mitigar los efectos de la pandemia, adoptando medidas de política fiscal que permitan una redistribución equitativa, incluyendo el diseño de planes y compromisos concretos para aumentar sustantivamente el presupuesto público y garantizar el derecho a la salud (Resolución 1/2020 CIDH).

La situación de precariedad económica de las personas con discapacidad debe ser central en las políticas fiscales y económicas, que tienen un enorme poder redistributivo. Estas medidas inmediatas de alivio económico deben asegurar el principio de no discriminación e incluir acciones afirmativas para asegurar que las personas con discapacidad no se quedan atrás (Resolución 1/2020 CIDH). Debiendo ser priorizadas en la adopción de medidas dirigidas a mitigar la pobreza, apoyar al sector informal, en el marco de las políticas crediticias, así como en el diseño de otros alivios fiscales (Oficina del Alto Comisionado de la ONU, 2020).

8 Que encuentran un mayor desarrollo en PALACIOS, A. (2020). 


\subsection{Una dimensión de reconocimiento para combatir el estigma, los estereotipos, los prejuicios y la violencia, y para reconocer la dignidad de los seres humanos y su interseccionalidad}

La OG6 integra en este punto diversas dimensiones complementarias, que incluyen: en primer lugar una política de reconocimiento para la inclusión de la diversidad como parte de la condición de humanidad (YOUNG, 2020). ${ }^{9}$ Por otro lado, la necesidad de seguir potenciando la dignidad desde una mirada holística, y finalmente, todo ello desde un enfoque que comprenda la identidad desde una mirada interseccional lo que significa una intersección de condiciones, pero también de situaciones y posiciones (BARRERE UNZUETA-TARAMUNDI, 2011).

Si repasamos la evolución de los valores que sustentan a los derechos humanos, podemos advertir que hasta que el modelo social no se infiltró, la construcción y justificación de dichos valores dejaba afuera justamente a las personas con discapacidad (además de haberlo hecho previamente con otras personas en base a su origen étnico, género, entre otras condiciones/posiciones). La idea de dignidad humana y su evolución refleja justamente esta afirmación. Frente a teorías filosóficas que caracterizaban una idea de dignidad humana claramente excluyente de la discapacidad, el movimiento de personas con discapacidad ha venido reclamando una caracterización universal, que involucre la igual dignidad de todas las personas (NUSSBAUM, 2007; STEIN, 2007).

La Observación General Nro 6 enfatiza asimismo en la idea de igual dignidad en la diversidad, exigiendo la consideración de que la vida de todas las personas, con o sin diversidad funcional, tiene el mismo valor, reclamando el respeto y la promoción de su autonomía y potenciando su aplicación coherente en todos los ámbitos (PALACIOS; ROMAÑACH, 2007). La dignidad apunta a la inviolabilidad de la persona, que repercute en el igual valor de las vidas de las personas con discapacidad y una política sanitaria que no discrimine en el acceso ni en las medidas frente a una potencial saturación del sistema de salud (CIDH, 2020b). Ello implica la prohibición de denegación de tratamiento por motivos de discapacidad y la derogación de disposiciones que impidan el acceso al tratamiento por motivos de discapacidad, nivel de necesidades de apoyo, evaluaciones de calidad de vida o cualquier otra forma de sesgo médico contra las personas con discapacidad, incluso dentro de directrices para la asignación de recursos escasos como los respiradores o el acceso a los cuidados intensivos (Oficina del Alto Comisionado de la ONU, 2020).

La Alta Comisionada de las Naciones Unidas para los Derechos Humanos, Michelle Bachelet, ha mostrado su preocupación respecto a que la vida de las personas con discapacidad pueda haber tenido un "peso diferente al de otros durante esta pandemia", habiendo expresado que le

\footnotetext{
inquietan profundamente determinados informes que indican que durante esta pandemia las vidas de las personas con discapacidad han sido menos valoradas que las de otros pacientes [...] y que las decisiones facultativas deben basarse en las evaluaciones clínicas individuales y las necesidades médicas, y no en la edad u otras características, tales como la discapacidad (ONU, 2020a).
}

En este sentido, se vienen planteando serias preocupaciones sobre los impactos discriminatorios de los protocolos de triaje que reflejen criterios que impliquen la negación o la eliminación de la atención de las personas con discapacidad, lo que resulta en discriminación y una vulneración de los derechos a la salud y la vida (Carta IDA, 2020). Lamentables ejemplos se han dado en diversos países, como en España, mediante un Protocolo sanitario que establecía la restricción del acceso al hospital a aquellas personas que, "aunque tengan infección respiratoria, no puedan ser independientes en sus movimientos o tengan alguna discapacidad intelectual". ${ }^{10}$ Dicha medida fue objeto de denuncia por parte del Comité Español de Representantes de Personas con Discapacidad (CERMI), y asimismo dio origen a una respuesta por parte del Comité de Bioética de España, explicando que

Protocolo sobre el que se dio marcha atrás en la Comunidad de Madrid como consecuencia de la denuncia pública realizada por el Comité sobre los Derechos de las Personas con Discapacidad (CERMI) https://www.cermi.es/es/actualidad/noticias/el-cermi-exige-que-no-se-discrimine-porraz\%C3\%B3n-de-discapacidad-en-los-protocolos https://www.elespanol.com/espana/madrid/20200325/polemico-documento-madrid-ancianosdiscapacidad-no-derivaran/477453553_0.html 
[...] resulta claro que la discapacidad de la persona enferma no puede ser nunca por sí misma un motivo que priorice la atención de quienes carecen de discapacidad. Ello vulneraría nuestro ordenamiento jurídico, concretamente la Convención sobre los Derechos de las Personas con Discapacidad, que exige garantizar el derecho a la vida y la atención sanitaria a las personas con discapacidad en igualdad de condiciones con todas las demás. Pero lesionaría de forma más flagrante principios éticos elementales, pues supondría entender que la vida de las personas con discapacidad tiene menos calidad y por tanto merece menos la pena atenderla, lo que resulta no solo absolutamente incoherente con la visión de la discapacidad que hoy tiene la sociedad española - reflejada en la Convención, pero también en nuestro ordenamiento jurídico interno, en particular en el Texto Refundido de la Ley General de Derechos de las Personas con Discapacidad y de su Inclusión Social, sino que supondría establecer una división entre vidas humanas en función de un supuesto valor de esas vidas arbitrariamente asignado o en función de su utilidad social. Señalábamos en nuestro Informe que, en una sociedad democrática, la titularidad de derechos no puede estar ligada a la posesión o no de un determinado nivel de conocimientos, habilidades o competencias (es decir, a una presunta "utilidad social" en los términos del debate que ahora nos ocupa) sino a la condición de persona, pues todas las personas tienen idéntico título para el reconocimiento y disfrute de sus derechos por el mero hecho de serlo. ${ }^{11}$

Otro ejemplo se presentó en Reino Unido, al elaborarse la Guía Rápida Covid-19 por parte del Instituto Nacional para la Excelencia en la Salud y la Atención (NICE 2020), mediante la cual se recomendaba priorizar los recursos de atención crítica en función de una Escala de fragilidad clínica. En su forma original, la Guía Rápida declaró que el CFS debe usarse porque ayuda a "identificar a los pacientes que tienen un mayor riesgo de malos resultados y que pueden no beneficiarse de las intervenciones de cuidados críticos". Sin embargo, como señalaron rápidamente las personas con discapacidad y sus organizaciones representativas, la descripción de "fragilidad" en el nivel 5 de SFC, por ejemplo, se aplicaría a personas más jóvenes con discapacidades, incluidas discapacidades intelectuales, parálisis cerebral, etc., que requieren ayuda con algunas actividades de la vida diaria pero, por lo demás, gozan de buena salud y no menos probabilidades que otras personas de la misma edad de recuperarse con tratamiento (SCULLY, 2020). ${ }^{12}$

Sin duda estas prácticas denotan una mirada hacia la discapacidad muy lejana a los valores que sustentan los derechos humanos, y muy propias del modelo de prescindencia de la discapacidad (PALACIOS, 2008), tanto en lo relativo a su salud como a la valoración de su calidad de vida. Ello nos enfrenta a la necesaria deconstrucción desde políticas que apunten e interpelen al reconocimiento, la dignidad y la inclusión de la perspectiva de discapacidad y enfoque de derechos humanos.

Resulta, por tanto, muy oportuna la recomendación de la Comisión Interamericana de Derechos Humanos (CIDH, 2020a), en cuanto encomienda adoptar de manera inmediata e interseccional el enfoque de derechos humanos en toda estrategia, política o medida estatal dirigida a enfrentar la pandemia y sus consecuencias. Desde las Naciones Unidas (ONU, 2020), en la misma línea, se establece que, para garantizar que las personas con discapacidad no se queden atrás, se requiere un enfoque de la discapacidad basado en los derechos humanos.

Sumado al enfoque de derechos humanos, sin duda es necesario adoptar una perspectiva de discapacidad. Si hacemos un paralelismo con la perspectiva de género, - que entiendo podría resultar pertinente -, la perspectiva de discapacidad es una herramienta conceptual y procedimental que persigue mostrar que la situación de desigualdad estructural en la que se encuentran inmersas las personas con discapacidad son la consecuencia de barreras físicas, comunicacionales, actitudinales y hasta legales, que

11 Informe del Comité de Bioética de España sobre los Aspectos Bioéticos de la priorización de recursos sanitarios en el contexto de la crisis del coronavirus, (23/03/2020), p.10 Incluso el Informe da un paso más a favor de un modelo de igualdad que contempla la necesidad de políticas de ajuste y medidas de acción positiva expresando que "en algunas ocasiones, ciertas personas con discapacidad, por la discapacidad concreta que presentan o las patologías asociadas a la misma, serán especialmente vulnerables frente al coronavirus. Este hecho, además de la evidencia de que todas las personas con discapacidad constituyen todavía en nuestro país un grupo social sujeto a una discriminación estructural y sistemática, permite considerar que uno de los criterios señalados por el art. 20.2 de la Ley de Cohesión y Calidad del Sistema Nacional de Salud, antes citado, concretamente el cuidado de los grupos menos protegidos o de riesgo, podría justificar la discriminación positiva en favor de las personas con discapacidad en las decisiones asistenciales, aplicando este criterio conjuntamente con los demás relacionados en el citado precepto. Idem, p.11

12 En respuesta a estas críticas, las Directrices NICE originales se modificaron para reconocer que el CFS es inapropiado para personas más jóvenes con discapacidades estables a largo plazo y que cualquier evaluación debe ser individualizada y holística. 
impiden el ejercicio de los derechos en condiciones de igualdad. Ello obliga a modificar los mecanismos, normas, prácticas y valores que reproducen la desigualdad (SCJM, 2013). E implica asegurar la incorporación de la discapacidad desde una perspectiva transversal, multidisciplinar e interseccional, en todas las actividades de respuesta a la Covid-19 (CIDH, 2020a).

En este sentido, la OG6 incorpora dentro de la dimensión del reconocimiento a la interseccionalidad. Como la CDPD ha demostrado, no es lo mismo el abordaje de la discapacidad desde un modelo médicorehabilitador, que desde el modelo social y desde el enfoque de derechos humanos. Lo mismo se ha verificado en cuanto a la existencia o no de la perspectiva de género (FACIO; FRIES, 2005). Estas son perspectivas absolutamente necesarias. Pero probablemente no suficientes, dado que asumir que los grupos se encuentran delineados en razón de categorías rígidas, como el género, la discapacidad, la orientación sexual o cualquier otra, implica invisibilizar aquellas situaciones que se encuentran justamente en la intersección entre dichas condiciones (FREDMAN, 2009). Es por ello que se requiere, además, la perspectiva de interseccionalidad.

La resolución $N^{\circ} 1 / 20$ de la CIDH exige que, al momento de emitir medidas de emergencia y contención frente a la pandemia, se deban aplicar perspectivas interseccionales. No puede perderse de vista que el confinamiento durante la pandemia incrementa la violencia contra las mujeres, y que asimismo obliga a las mujeres con discapacidad a estar encerradas con sus maltratadores. En el caso de niñas y niños, es sabido que también el encierro genera un aumento de la violencia sexual. El confinamiento hace que estén más expuestas y expuestos al abuso y la violencia, a lo que se adiciona el riesgo de abandono y exclusión escolar postpandemia.

Y las denuncias se dificultan por razones de género, niñez y discapacidad. Los servicios de atención y protección contra la violencia no están diseñados para responder ante la situación derivada de la emergencia (WOMEN ENABLED INTERNATIONAL, 2020). Es necesario entonces garantizar que los mecanismos de denuncia y asistencia a las víctimas sean accesibles para las personas con discapacidad, y que se garanticen ajustes procedimentales en el derecho de acceso al sistema de justicia (UNICEF, 2020).

\subsection{Dimensión participativa para reafirmar el carácter social de las personas como miembros de grupos sociales y el reconocimiento pleno de la humanidad mediante la inclusión en la sociedad}

La OG6 refiere a una dimensión participativa. Las personas con discapacidad son protagonistas y deben participar desde el inicio en la planificación e implementación de toda respuesta ante la pandemia. Asimismo, deben asegurarse de que las políticas y los programas respondan y se adapten a las diferentes necesidades con la debida consideración a la interseccionalidad y que no creen o exacerben la desigualdad (Oficina del Alto Comisionado de la ONU, 2020). Las personas con discapacidad tienen importantes contribuciones que hacer en este contexto. Muchas tienen experiencia en situaciones de aislamiento y en modalidades de trabajo alternativas que pueden servir de modelo para la situación actual. Sus perspectivas y vivencias contribuyen a la creatividad, a nuevos enfoques y a soluciones innovadoras. $Y$ es por ello que deben desempeñar un papel clave en la promoción de una respuesta a la crisis que incluya la discapacidad (IDA, 2020).

Sumado a lo anterior, como ha solicitado la Alianza Internacional de Discapacidad, es importante que los Estados incorporen la evaluación del impacto de la igualdad como un elemento integral de sus continuas respuestas de salud pública, así como de las políticas económicas y sociales a la crisis. Se debe garantizar que la evaluación del impacto de la igualdad sea un elemento esencial de su monitoreo y revisión de las respuestas de política a la pandemia y de sus efectos sobre el terreno. Tanto las evaluaciones iniciales como el monitoreo continuo deben estar informados por la recopilación de datos sobre las experiencias y los resultados de los grupos expuestos a la discriminación (Carta IDA, 2020). La ONU destaca la necesidad de contar con datos a dichos fines. $\mathrm{E}$ insta asimismo a establecer mecanismos de rendición de cuentas para asegurar la inclusión de la discapacidad en la respuesta (ONU, 2020).

La CIDH (2020) ha puesto énfasis en la obligación de asegurar la participación de personas con discapacidad en el diseño, la implementación y el monitoreo de las medidas adoptadas frente a la pandemia. También la alta comisionada de la ONU exige consultar estrechamente e involucrar activamente a las personas 
con discapacidad en la elaboración de una respuesta basada en derechos, inclusiva de la discapacidad en toda su diversidad. La ONU (2020), en el mismo sentido, define como esfera de acción la celebración de consultas sustantivas y la participación activa en todas las fases de la respuesta y en la recuperación posterior.

Debe advertirse que a fin de garantizar una verdadera participación, es importante el acceso a la información. En dicho sentido, ha expresado la CIDH (2020b) que para garantizar el adecuado ejercicio de los derechos de las personas con Covid-19 los Estados tienen la obligación positiva de informar de manera proactiva a las personas sobre sus derechos frente a prestadores de salud, así como los mecanismos de protección existentes. Esto también incluye la obligación de facilitar el conocimiento y acceso a información culturalmente adecuada y particularmente accesible a los distintos grupos de población sobre medidas de prevención y de atención de salud en este contexto.

\subsection{Dimensión de ajustes para dar cabida a la diferencia como aspecto de la dignidad humana}

La Observación General № 6 del Comité sobre los Derechos de las Personas con Discapacidad destaca que la adopción de ajustes implica el reconocimiento de la diversidad como parte de la condición y de la dignidad humana, y a su vez la falta de adopción de ajustes razonables es una discriminación.

Las respuestas desde la política pública deben garantizar un abordaje no discriminatorio en razón de discapacidad y, a la vez, una mirada y un trato inclusivos. Esto implica, en primer lugar, que las respuestas frente a la pandemia no resulten discriminatorias. La CDPD entiende por discriminación

cualquier distinción, exclusión o restricción por motivos de discapacidad que tenga el propósito o el efecto de obstaculizar o dejar sin efecto el reconocimiento, goce o ejercicio, en condiciones de igualdad, de todos los derechos humanos y libertades fundamentales en los ámbitos político, económico, social, cultural, civil o de otro tipo. Esto incluye todas las formas de discriminación, y, entre ellas, la denegación de ajustes razonables (CDPD art. $2^{\circ}$ ).

Se destaca que la obligación de prohibir toda discriminación por motivos de discapacidad no comprende solo a las personas con discapacidad, sino a cualquier persona que pueda ser discriminada "por motivo de discapacidad". Ello incluye a las personas de su entorno, su familia, y profesionales que trabajen para ellas. La protección contra "todas" las formas de discriminación incluye, entre otras, discriminación directa, discriminación indirecta, denegación de ajustes razonables y acoso.

La relatora de la ONU sobre discapacidad (2020) explica que las medidas de contención, como el distanciamiento social y el aislamiento personal, pueden ser imposibles para quienes requieren apoyo para comer, vestirse o ducharse. El apoyo es básico para su supervivencia, y se deben tomar medidas adicionales de protección social para garantizar su continuidad y a lo largo de la crisis. La planificación debe considerar que las restricciones de movilidad impactan desproporcionadamente a las personas con movilidad reducida y otras con discapacidad, y por ello exigen adaptaciones. Asimismo, es importante no perder de vista que las políticas de reconocimiento se vinculan con el diseño y la accesibilidad universal. El reconocimiento de la diversidad implica dar un salto cualitativo hacia la "aceptación de las personas con discapacidad como parte de la diversidad y la condición humanas" (CDPD, art. $3^{\circ}$ ). Ello obliga al diseño de la política pública inclusiva, en clave de diseño universal, a la vez que de ajustes.

Entre las directrices elaboradas por la $\mathrm{CIDH}(2020 \mathrm{~b})$ con el fin de garantizar y respetar el ejercicio de los derechos a la vida y a la salud de las personas con Covid-19, se impone a los Estados el deber de velar por la accesibilidad y asequibilidad a las aplicaciones tecnológico-científicas, en condiciones de igualdad. De igual modo, se establece que toda persona con Covid-19 tiene derecho a que la información le sea suministrada de manera clara, accesible y culturalmente adecuada. De este modo, las respuestas frente a la pandemia deben garantizar la no discriminación en razón de discapacidad y a la vez incluir la perspectiva de discapacidad y los ajustes pertinentes. Ello requiere un diseño que garantice la accesibilidad universal.

Es posible diferenciar tres proyecciones - complementarias - de la accesibilidad. Por un lado, se puede considerar a la accesibilidad universal como parte del contenido esencial de los derechos. Por otro, la accesibilidad universal puede ser entendida como parte del contenido específico del derecho a la no 
discriminación. Asimismo, la accesibilidad universal puede ser caracterizada como un derecho subjetivo autónomo. ${ }^{13}$ Estas dimensiones descriptas no son excluyentes sino complementarias, pero no debemos olvidar que asimismo estamos hablando de un derecho, autónomo e instrumental para el ejercicio del resto (PALACIOS; FERNÁNDEZ; IGLESIAS, 2020).

Teniendo presente lo antedicho, garantizar la igualdad y la no discriminación en materia de discapacidad implica prever un diseño universal de las políticas, es decir con perspectiva de discapacidad y, asimismo, un enfoque diferencial que incluya la adopción de ajustes razonables cuando se requieran. A estas medidas para la igualdad deberán sumarse acciones positivas y redistributivas. Así, ha explicado la CIDH (2020a) que las medidas inmediatas de alivio económico deben asegurar el principio de no discriminación e incluir acciones afirmativas para asegurar que las personas con discapacidad no se queden atrás. En esta línea, esta resolución exige justamente, con relación a las disposiciones que se adopten en el marco de la pandemia, considerar los enfoques diferenciados requeridos al momento de adoptar las medidas necesarias para garantizar los derechos de los grupos en situación de especial vulnerabilidad en materia de atención, tratamiento y contención de la pandemia; así como para mitigar los impactos diferenciados que dichas medidas puedan generar.

Y teniendo en cuenta los impactos diferenciados, merecen especial atención las personas con discapacidad que viven en instituciones. En estos contextos, se requiere también una especificidad que brinde condiciones de accesibilidad durante el encierro, como por ejemplo el acceso a medidas de seguridad frente al contagio, o ajustes como el acceso a la comunicación con sus familias. Esto último para garantizar canales de denuncia si fueran necesarios, dado que limitar el contacto con sus seres queridos deja a las personas con discapacidad totalmente desprotegidas frente a cualquier forma de abuso o negligencia (relatora de la ONU sobre discapacidad, 2020).

Estas situaciones también han sido visibilizadas por la ONU (2020b), recomendando, entre otras acciones, preparar las instituciones para prevenir y responder a posibles infecciones, reducir el número de personas internadas en ellas, así como la cantidad de personas con discapacidad en las cárceles. Asimismo, se ha reforzado la necesidad de que a las personas con discapacidad se les resguarde su salud mental, prohibir el uso del aislamiento, restricciones, medicación no consensuada u otros tratamientos que inflijan sufrimiento y/o que comprometan el sistema inmunológico de la persona, proveer el acceso oportuno a la información accesible sobre Covid-19, facilitar el contacto telefónico o virtual con familiares y amigos, y efectuar supervisiones regulares a estos recintos para el cumplimiento de las medidas anteriormente señaladas y para evitar todo tipo de negligencia, abuso o abandono (Oficina del Alto Comisionado de la ONU, 2020).

\section{Conclusiones}

El desarrollo de las dimensiones descritas en este trabajo forman parte de los estándares que el derecho internacional de los derechos humanos exige en materia de discapacidad en el contexto de pandemia.

La dimensión redistributiva de la igualdad exige mayor inclusión de la discapacidad en las políticas de desarrollo. La situación de precariedad económica en la que vive la mayoría de de las personas con discapacidad debe ser central en las políticas fiscales y económicas. Pero también es necesario que dichas políticas tengan presente la inclusión de la discapacidad desde una mirada transversal en todos los ámbitos y de manera participativa. Ello se relaciona con la redistribución, pero desde una mirada integral de la discapacidad, que habilite una identidad que debe estar concebida y conformada desde el propio colectivo.

La dimensión de reconocimiento justamente implica y exige profundizar sobre la "condición" de discapacidad - diversidad funcional - desde un criterio identitario, que supere el enfoque del diagnóstico médico - aun denominado deficiencia. Y ello significa superar una mirada a partir de un diagnóstico que

13 Esta última dimensión ha sido asumida por la Convención Interamericana sobre la Protección de los Derechos Humanos de las Personas Mayores, art. 26. 
coloniza - y arrasa- la vida. También resulta imperativo sumar la perspectiva de interseccionalidad. Estas dimensiones enriquecen la mirada, a la vez que fortalecen el respeto de la diversidad funcional de una persona como un elemento natural de la diversidad humana, permitiendo abordar los prejuicios específicos, los estereotipos, la invisibilidad, la violencia y otras vulneraciones, desde una mirada holística. De este modo, si la mirada deja de ser reduccionista, las respuestas desde la política pública también podrían dejar de serlo.

En cuanto a la dimensión de participación, también parece necesario e imperioso habilitar y potenciar las voces protagonistas de este proceso. La propia CDPD ha sido un ejemplo con muy buenos resultados. En mayor medida que otros Tratados de derechos humanos, ha brindado y brinda espacio a las organizaciones de la sociedad civil como agentes es su elaboración e implementación. Las personas con discapacidad han sido y son actores indiscutides en todo ese proceso, pero hoy sigue siendo necesario trabajar en medidas y metodologías que permitan una verdadera participación.

También se hace necesario recordar que la igualdad debería ser asimismo un parámetro de evaluación de la política pública. La evaluación del impacto de la igualdad debería ser un elemento integral de las políticas públicas. Es solo a través de la evaluación de los impactos en la igualdad de sus respuestas políticas que los Estados pueden garantizar que sus acciones cumplan con sus obligaciones vinculantes de no discriminación en virtud del derecho internacional. Y claramente no es posible medir el impacto sin la participación de las personas con discapacidad.

Finalmente, en cuanto a la última dimensión - ajustes para dar cabida a la diferencia, sin duda se hace necesario el desarrollo del contenido y alcance de la accesibilidad universal. Profundizando sus diversas dimensiones - como principio, como parte del derecho a la no discriminación, como parte del contenido esencial de cualquier derecho, y sobre todo, como derecho autónomo. Es en el contexto de la comprensión del contenido y alcance de la accesibilidad universal sin duda desde donde deben analizarse los ajustes razonables y los sistemas de apoyos. Como herramientas jurídicas que potencian, a veces la accesibilidad universal; y que conforman, otras, el contenido esencial de los derechos.

El modelo de igualdad inclusiva que asume la el Comité sobre los Derechos de las Personas con Discapacidad se plantea como una herramienta transformativa. El creciente compromiso a nivel internacional alumbra el camino en el sentido de lo sustantivo. Las cuatro dimensiones descritas crean una concepción compleja y dinámica del derecho a la igualdad, que se basa en entendimientos preexistentes, pero que a la vez invita a un mayor desarrollo y evolución de sus fundamentos.

La pandemia nos interpela a deconstruirnos, y en dicha deconstrucción conjunta, resulta fundamental seguir profundizando en el marco conceptual y legal de estas dimensiones y sus implicancias en el contexto de la discapacidad. El modelo de igualdad inclusiva podría ser concebido como un horizonte - en los términos de Galeano -, que nos impulse a caminar hacia una política inclusiva en materia de discapacidad - que tristemente hoy sigue siendo una utopía. La situación que hoy vivimos como humanidad sin duda lo requiere.

\section{Referencias}

BARNES, Colin; OLIVER, Mike; BARTON, Len (ed.). Disability studies today. Polity Press: Oxford, 2002.

BARRERE UNZUETA, María Ángeles; TARAMUNDI, Dolores. Subordinación y discriminación interseccional: elementos para una teoría del derecho antidiscriminatorio. Anales de la Cátedra Francisco Suárez, Granada, v. 45, p. 15-42, 2011.

CEA MADRID, Juan Carlos (ed.). Por el derecho a la locura: la reinvención de la salud mental en América Latin. Santiago: Editorial Proyección, 2019.

COMITÉ SOBRE LOS DERECHOS DE LAS PERSONAS CON DISCAPACIDAD. Observación general No 6 (2018) sobre la igualdad y la no discriminación. Ginebra: UN, 26 abr. 2018.

CRENSHAW, Kimberle. Demarginalizing the intersection of race and sex: a black feminist critique of antidiscrimination doctrine, feminist theory and antiracist politics. University of Chicago Legal Forum, Chicago, v. 1989, issue 1, article 8, p. 139-167, 2015. 
DE ASÍS ROIG, Rafael. Sobre discapacidad y derechos. Madrid: Dykinson, 2013.

FACIO, Alda; FRIES, Lorena. Feminismo, género y patriarcado. Academia. Revista sobre Enseñanza del Derecho de Buenos Aires, Buenos Aires, año 3, n. 6, p. 259-264, Primavera 2005.

FERRANTE, Carolina. En memoria de Mike Oliver: un legado sociológico vivo para los estudios críticos latinoamericanos en discapacidad. Boletín Científico Sapiens Research, Bogotá, v. 9, n. 2, p. 80-90, 2019. Disponible en: https://www.srg.com.co/bcsr/index.php/bcsr/article/view/354. Acceso en: 10 jun. 2020.

FERREIRA, Miguel Ángel. La construcción social de la discapacidad: habitus, estereotipos y exclusión social. Nómadas, Revista Crítica de Ciencias Sociales, Madrid, v. 17, n. 1, p. 1-13, 2008.

FREDMAN, Sandra. Positive rights and positive duties: addressing intersectionality. En: SCHIEK. D.; CHEGE, V. (ed.). European Union non discrimination law: comparative perspectives on multidimensional equality law. Abingdon: Routledge-Cavendish, 2009. p. 73-90.

FREDMAN, Sandra. Substantive equality revisited. International Journal of Constitutional Law, Oxforfd, v. 14, Issue 3, p. 712-738, july 2016. Disponible en: https://doi.org/10.1093/icon/mow043. Acceso en: 10 jun. 2020.

FREDMAN, Sandra et al. Achieving transformative equality for persons with disabilities: submission to the CRPD Committee for General Comment No. 6 on Article 5 of the UN Convention on the Rights of Persons with Disabilities. Oxford: Oxford University, 2017. Disponible en: http://ohrh.law.ox.ac.uk/ wordpress/wp-content/uploads/2017/12/CPRD-Submission.pdf. Acceso en: 12 jun. 2020.

GOLDSCHMIDT, Jenny E. New perspectives on equality: towards transformative justice through the disability convention?. Nordic Journal of Human Rights, Oslo, v. 35, n. 1, p. 1-14, 2017.

HUETE GARCIA, Agustin, Pandemia y discapacidad: lecciones a propósito del confinamiento. Salamanca: Inico, 2020.

INTERNATIONAL DISABILITY ALLIANCE. Carta IDA: abordar la discriminación y la desigualdad en la respuesta global a Covid-19. Genebra: IDA, [2020]. Disponible en: http://www. internationaldisabilityalliance.org/content/covid-19-and-disability-movement. Acceso en: 14 abr. 2020.

INTERNATIONAL DISABILITY ALLIANCE. Hacia una respuesta inclusiva de la discapacidad frente a la Covid-19: 10 recomendaciones de la Alianza Internacional de Discapacidad. IDA, Genebra, 19 mar. 2020. Disponible en: https://www.internationaldisabilityalliance.org/sites/default/files/ida_recomendaciones_ para_una_respuesta_inclusiva_de_la_discapacidad_frente_al_covid19.pdf. Acceso en: 14 abr. 2020. MARTÍNEZ RÍOS, Beatriz. Pobreza, discapacidad y derechos humanos. Revista Española de Discapacidad, Madrid, v. 1, n. 1, p. 9-32, 2013.

MCRUER Robert. Crip times: disability, globalization and resistance. Nueva York: NYU Press, 2018.

MEXICO. Suprema Corte de Justicia de la Nación. Protocolo para juzgar con perspectiva de género: haciendo realidad el derecho a la igualdad. Mexico, D.F.: Suprema Corte de Justicia de la Nación, 2013. Disponible en: http://archivos.diputados.gob.mx/Comisiones_LXII/Igualdad_Genero/PROTOCOLO.pdf. Acceso en: 20 mar. 2020.

NUSSBAUM, Marta. Las fronteras de la justicia: consideraciones sobre la exclusión. Traducción: Ramón Vila Vernis y Albino Santos Mosquera. Barcelona: Paidos, 2007.

OSPINA RAMÍREZ, Mario A. EI reconocimiento de la capacidad jurídica dentro de un contexto de igualdad: una asignatura pendiente del Estado colombiano. Bogotá: Universidad Externado de Colombia, 2018.

ORGANIZAÇÃO DOS ESTADOS AMERICANOS. Comisión Interamericana de Derechos Humanos.

Pandemia y derechos humanos en las Américas: resolución N 1/2020. Washington: OEA, 10 abr. 2020. Disponible en: https://www.oas.org/es/cidh/decisiones/pdf/Resolucion-1-20-es.pdf. Acceso en: 10 jun. 2020.

ORGANIZAÇÃO DOS ESTADOS AMERICANOS. Comisión Interamericana de Derechos Humanos.

Derechos humanos de las personas con Covid-19: resolución № 4/20. Washington: OEA, 27 de jul. 
2020. Disponible en: https://www.oas.org/es/cidh/decisiones/pdf/Resolucion-4-20-es.pdf. Acceso en: 10 ago. 2020.

ORGANIZACIÓN DE LAS NACIONES UNIDAS. Oficina del Alto Comisionado de la ONU. Covid-19 y los derechos de las personas con discapacidad: directrices. Ginebra: ONU, 30 abr. 2020. Disponible en: https://www.ohchr.org/Documents/Issues/Disability/COVID-19_and_The_Rights_of_Persons_with_ Disabilities_SP.pdf. Acceso en: 12 jun. 2020.

ORGANIZACIÓN INTERNACIONAL DEL TRABAJO. Nadie se quede atrás, ni ahora ni nunca: personas con discapacidad en la réplica a la Covid 19. Ginebra: OIT, 8 abr. 2020. Disponible en: https:// www.ilo.org/global/topics/disability-and-work/WCMS_741305/lang--es/index.htm. Acceso en: 12 jun. 2020.

ORGANIZACIÓN DE LAS NACIONES UNIDAS. Declaraciones de la Alta Comisionada para los Derechos Humanos. Ginebra: ONU, 30 abr. 2020.

ORGANIZACIÓN DE LAS NACIONES UNIDAS. Informe de políticas: una respuesta a la Covid-19 inclusiva de la discapacidad. Ginebra: ONU, 2020. Disponible en: https://www.un.org/sites/un2.un.org/ files/spanish_disability_brief.pdf. Acceso en: 12 jul. 2020.

ORGANIZACIÓN DE LAS NACIONES UNIDAS. Covid-19 and human rights: we are all in this together. Ginebra: ONU, 23 abr. 2020. Disponible en: https://www.un.org/en/un-coronavirus-communications-team/ we-are-all-together-human-rights-and-covid-19-response-and? Acceso em: 23 jun. 2020.

ORGANIZACIÓN DE LAS NACIONES UNIDAS. Relatora de la ONU sobre Discapacidad: Covid-19: ¿quién protege a las personas con discapacidad?. Ginebra: ONU, 17 mar. 2020. Disponible en: https://www. ohchr.org/SP/NewsEvents/Pages/DisplayNews.aspx?NewsID=25725\&LangID=S. Acceso en: 27 abr. 2020.

OXFAM. EI coronovirus no discrimina, las desigualdades si: encer la pandemia requiere enfrentar las desigualdades. Oxford: OXFAM, mar. 2020. Disponible en: https://oi-files-d8-prod.s3.eu-west-2. amazonaws.com/s3fs-public/2020-03/Covid\%2019\%20en\%20LAC_nota\%20informativa_F_0.pdf. Acceso em: 10 jun. 2020.

PALACIOS, A.; ROMAÑACH, J. El modelo de la diversidad: la bioética y los derechos humanos como herramienta para alcanzar la plena dignidad en la diversidad funcional. Madrid: Diversitas, 2007.

PALACIOS, Agustina. El modelo social de discapacidad: orígenes, caracterización y plasmación en la Convención Internacional sobre los Derechos de las Personas con Discapacidad. Madrid: Cinca, 2008.

PALACIOS, A.; FERNÁNDEZ, S.E.; IGLESIAS, M.G. Situaciones de discapacidad y derechos humanos. Buenos Aires: Thomson Reuters, 2020.

PALACIOS, Agustina. ¿Un nuevo modelo de derechos humanos de la discapacidad? Algunas reflexiones -ligeras brisas- frente al necesario impulso de una nueva ola del modelo social. Revista Latinoamericana en Discapacidad, Sociedad y Derechos Humanos, Mar del Plata, v. 4, n. 2, p. 12-42, año 2020.

PALACIOS, A.; GONZÁLEZ BONET, V. Personas con discapacidad: una oportunidad de deconstrucción para la inclusión. En: BOHOSLAVSKY, J.P. (ed.). Covid-19 y derechos humanos: la pandemia de la desigualdad. Buenos Aires: Biblos, 2020.

RIBOTTA, Silvina. Las desigualdades económicas en las teorías de la justicia: pobreza, redistribución e injusticia social. Madrid: Centro de Estudios Políticos y Constitucionales, 2010.

SERRA, María Laura. Mujeres con discapacidad: sobre la discriminación y opresión interseccional. Madrid: Dykinson, 2017.

STEIN, Michael. Disability human rights. California Law Review, Berkeley, v. 95, n.1, p. 1-63, 2007.

TOBOSO MARTíN, Mario. Capacitismo. En: PLATERO, R.; ROSÓN, María; ORTEGA, Esther (ed.). Barbarismos queer y otras esdrújulas. Barcelona: Ed. Bellaterra, 2017. p. $73-81$.

WOMEN ENABLED INTERNATIONAL. Country Support Policy Brief 2: Meeting basic needs for Women and Girls with Disabilities during Covid-19. New York: UN Women, 2020. 
YARZA DE LOS RIOS, Alexander et al. Estudios críticos en discapacidad: una polifonía desde América Latina. Buenos Aires: Clacso, 2019.

YOUNG, Iris Marion. La justicia y la política de la diferencia. Traducción: Silvina Álvarez. Madrid: Cátedra; Universidad de Valencia, 2000.

Recebido em: 12/10/2020

Aprovado em: 07/12/2020 